\title{
JAEA Fatigue Analysis of EBR-II Duplex Tubing
}

\author{
J. H. Jackson \\ D. L. Porter \\ W. R. Lloyd \\ July 2009
}

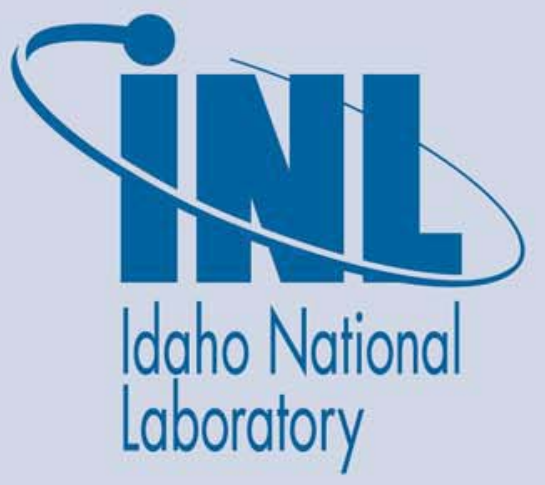

The INL is a U.S. Department of Energy National Laboratory operated by Battelle Energy Alliance 
INL/EXT-09-16354

\title{
JAEA Fatigue Analysis of EBR-II Duplex Tubing
}

\author{
J. H. Jackson \\ D. L. Porter \\ W. R. Lloyd
}

July 2009

\section{Idaho National Laboratory \\ Idaho Falls, Idaho 83415}

http://www.inl.gov

Prepared for the

Japanese Atomic Energy Agency

WFO Contract 08901

Under DOE Idaho Operations Office

Contract DE-AC07-05ID14517 


\section{Introduction}

This work addresses questions brought up concerning the mechanisms associated with fatigue crack growth retardation and/or arrest within the nickel bond layer in duplex 21/4 $\mathrm{Cr}$-1Mo steel superheater tubes. Previous work performed at the Idaho National Laboratory (INL) indicated that the nickel bond layer did not function as a crack arrestor during fatigue crack propagation with the exception of one, isolated case involving an exceptionally low fatigue load and a high temperature $\left(400^{\circ} \mathrm{C}\right)$ environment. Since it is atypical for a fatigue crack to propagate from a relatively soft material (the nickel bond layer) to a harder material (the $2 \frac{1}{4} \mathrm{Cr}$-1Mo steel) there has been speculation that the nickel bond layer was hardened in service. Additionally, there are questions surrounding the nature of the fatigue crack propagation within the nickel bond layer; specifically with regard to the presence of voids seen on micrographs of the bond layer and oxidation within the steel along the edge of the nickel bond layer. There is uncertainty as to the effect of these voids and/or oxide barriers with respect to potential fatigue crack arrest.

\section{Material and Testing Procedures}

\subsection{Testing of surrogate samples}

To establish confidence in the ability to measure fatigue crack growth in nontypical fracture specimens (Charpy v-notch) using the DC Potential drop method with Johnson's equation for crack length prediction, several $2 \frac{1}{4} \mathrm{Cr}-1 \mathrm{Mo}$ steel surrogate specimens were fatigued. The typical specimen geometry is shown in Figure 1. It should be noted that these specimens are non-standard in that the width "W" is small, relative to thickness "B" and load span "S" according to ASTM Standard E647 for fatigue testing of metals, and the notch radius is atypically large relative to the dimension "W". Additionally, the effect of the presence of the nickel interlayer, which creates a non-homogenous electrical cross section, is unknown. As such, several fatigue tests were performed using surrogate specimens that were fabricated entirely from $2 \frac{1}{4} \mathrm{Cr}-1 \mathrm{Mo}$ steel to ensure that there was not a major effect caused by the electrical inhomogeneity. It is assumed that the minor effect of the atypically large notch radius was only an issue for the very beginning of the crack growth. 

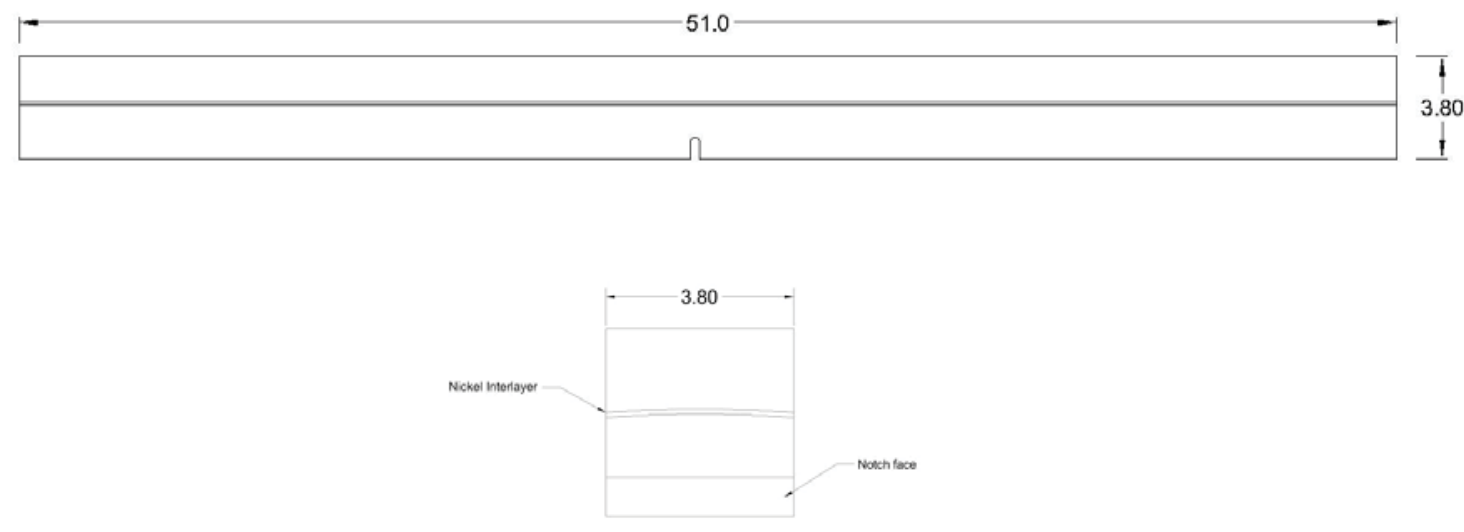

Figure 1: Typical fatigue specimen.

\subsection{Fatigue testing}

Several specimens remained from the previous study performed at INL in 2006. Specimens from both the upper and lower sections (sodium outlet, steam inlet and sodium inlet and steam outlet, respectively) of duplex tubing from an EBR-II superheater were used in this study; no differentiation between upper and lower was made for this work since it was simply an investigation into the potential for crack arrest in the nickel interlayer and it was noted in the previous study [1] that fatigue behavior from the two regions was similar. As in the previous study, Charpy shaped, 3 point bend specimens (Figure 1) were fatigued in the nearthreshold $\Delta \mathrm{K}\left(\sim 11 \mathrm{MPa}-\mathrm{m}^{1 / 2}\right)$ and steady-state $\Delta \mathrm{K}\left(\sim 15 \mathrm{MPa}-\mathrm{m}^{1 / 2}\right)$ regimes of the Paris law da/dN $-\Delta \mathrm{K}$ curve. The objective was to intentionally (if possible) force the fatigue crack to arrest in the nickel interlayer by utilizing a near threshold $\Delta \mathrm{K}$. Additionally, a test was performed to re-create the fatigue characteristics observed in the previous study [1], whereby the fatigue crack was observed to slow down in the interlayer and accelerate upon passing through it. All tests were performed in air at room temperature as the previous study noted no effect 
of elevated temperature on fatigue behavior of the specimens. A servo-hydraulic Instron, model 8501 test frame with a $5 \mathrm{KN}$ load cell was used to enforce a sinusoidal waveform loading pattern of nominally $20 \mathrm{~Hz}$ with a loading ratio $\mathrm{R}=0.1$. A reversing current, $\mathrm{DC}$-potential drop method was used to monitor crack growth and a 50X optical microscope was used to monitor crack growth on the surface of the specimens for comparison.

\subsection{Characterization of nickel interlayer}

It is hypothesized [1] that the nickel interlayer may have become hardened in service. This in-service hardening could potentially explain the observed phenomena of increased crack growth rate (CGR) when the nickel interlayer is encountered. To address this possibility, micro-hardness measurements were made along the nickel interlayer, as well as in the base material in specimen SU710-U-9 and SU710-U-12. The nickel interlayer is an approximately $10 \% \mathrm{P}$ content Ni-P braze that was formed by a combination of electroless nickel plating and electrodeposition on the outer surface of the inner tube, and the inner surface of the outer tube, respectively [1]. This roughly corresponds to a medium phosphorous content Ni-P braze that typically would be considered to have hardness ranging from approximately $400 \mathrm{Hv}$ to $900 \mathrm{Hv}$, depending on applied heat treatment [3].

\section{Results and Analysis}

\subsection{Surrogate (non-duplex) baseline samples}

Several specimens were machined from 2-1/4 Cr-1Mo steel to the same dimensions as the pre-existing steam generator tube specimens and fatigue tested in order to establish a test procedure and to provide a baseline for the DCPotential Drop crack size data. These were tested at a nominal $\Delta \mathrm{K}$ of $16 \mathrm{MPa}-$ $\mathrm{m}^{1 / 2}$ and load ratio of $\mathrm{R}=0.1$ to obtain steady-state Paris Law behavior. The resulting fatigue crack growth rate at this applied $\Delta \mathrm{K}$ and load ratio stabilized at approximately $2.92 \times 10^{-5} \mathrm{~mm} /$ cycle. This compares well with the fatigue crack growth rates noted in [1] for base 2-1/4 $\mathrm{Cr}-1$ Mo steel. Figure 2 shows this trend for one of the surrogate specimens. The initial loading slope is noticeably slower than the steady-state crack growth rate due to anomalies related to the large notch radius relative to the width $(\mathrm{W})$ of the specimen. This is expected in all specimens to be tested in this study and is not of concern since it only affects the first $\sim 0.1-0.2 \mathrm{~mm}$ of crack growth. 


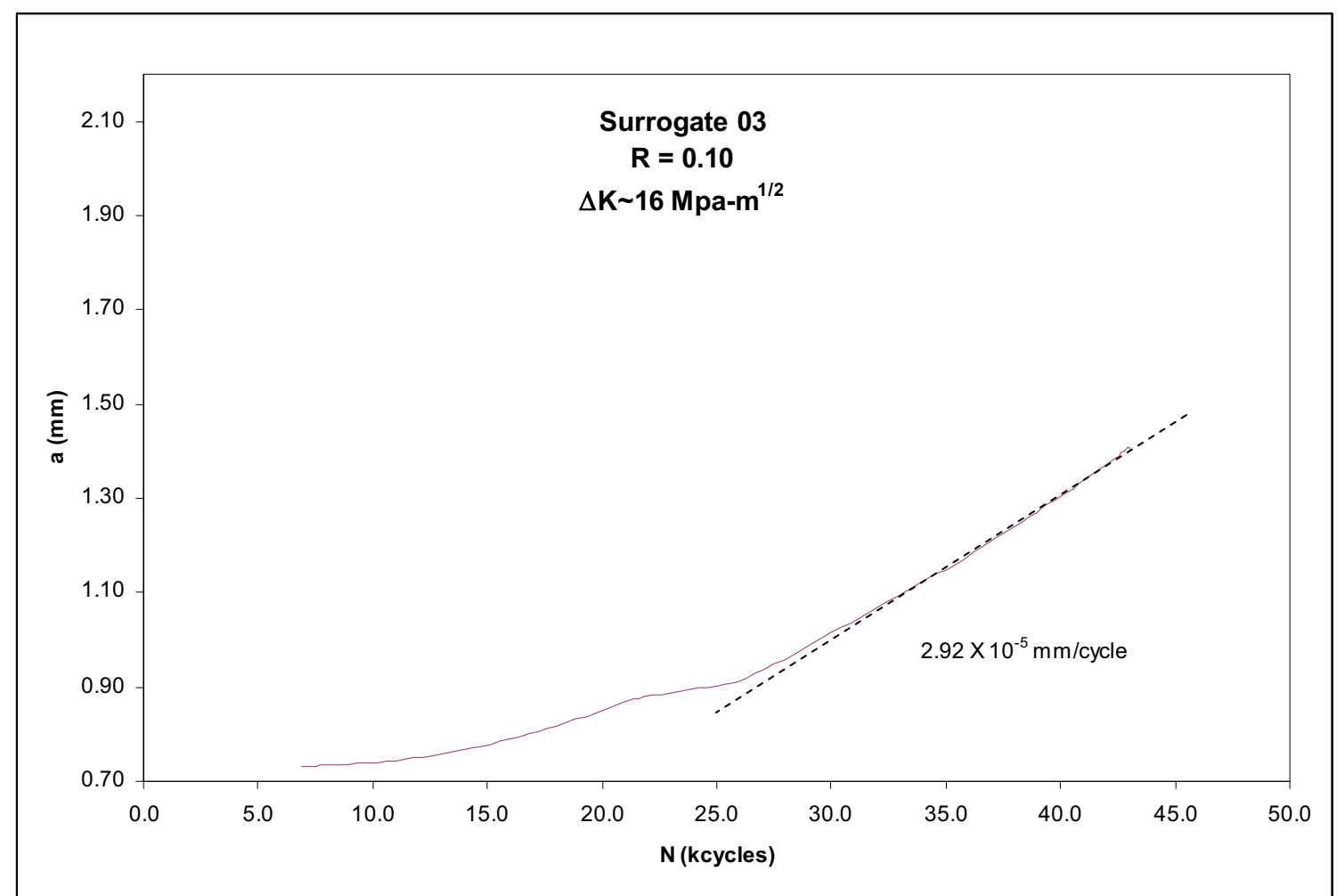

Figure 2: Crack growth vs. cycles for surrogate sample.

\subsection{Comparison to previous work}

In order to ensure consistency with previously performed work at INL, one specimen from the upper part of the heat exchanger was fatigue cracked at a constant, nominal $\Delta \mathrm{K}$ of $15 \mathrm{MPa}-\mathrm{m}^{1 / 2}$. The previous work had noted typical fatigue behavior within this Paris law region of the da/dN- $\Delta \mathrm{K}$ curve to be approximately $2.5 \times 10^{-5} \mathrm{~mm} /$ cycle up to the nickel interlayer. This was followed by a rate increase through the interlayer to approximately $3.5 \times 10^{-5} \mathrm{~mm} / \mathrm{cycle}$, and then was retarded to a growth rate of slightly less than $1.0 \times 10^{-5} \mathrm{~mm} / \mathrm{cycle}$ for a short distance beyond the nickel interlayer.

The specimen fatigued in the current study at a nominal $\Delta \mathrm{K}$ of $15 \mathrm{MPa}-\mathrm{m}^{1 / 2}$ followed roughly similar trends of a constant rate followed by an acceleration through the nickel interlayer and a retardation on the opposite side of the interlayer. The rates observed in the current study were $2.5 \times 10^{-5} \mathrm{~mm} /$ cycle, $2.92 \times 10^{-5} \mathrm{~mm} /$ cycle, and $1.03 \times 10^{-5} \mathrm{~mm} /$ cycle for the regions prior to, within, and beyond the nickel interlayer respectively. Figure 3 shows this behavior in a crack length vs. number of cycles (a-vs-N) plot for constant $\Delta \mathrm{K}$. It is noted that there is a gap in the data due to a correction made based on visual observation of the crack length the specimen surface through an optical microscope. This peculiarity does not affect the overall observed fatigue behavior. 


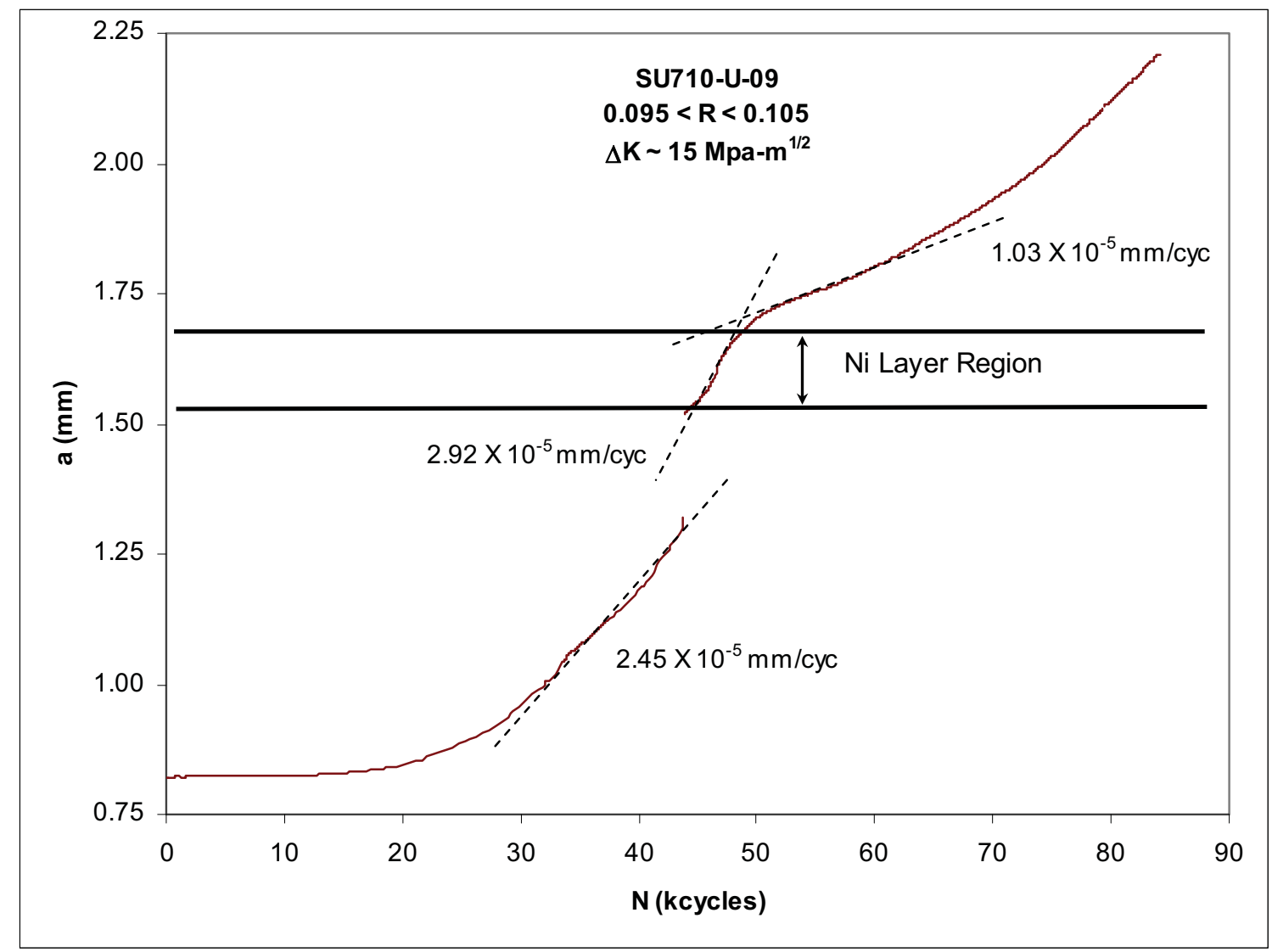

Figure 3: Fatigue behavior under Paris Law conditions $\left(\Delta \mathrm{K}=15 \mathrm{MPa}-\mathrm{m}^{1 / 2}\right)$ showing characteristic retardation of crack growth following nickel interlayer.

\subsection{Near threshold $\Delta \mathrm{K}$}

In the study performed previously at INL [3], a single specimen that was tested in air at elevated temperature $\left(400^{\circ} \mathrm{C}\right)$ exhibited crack arrest when tested at a near threshold $\Delta \mathrm{K}$ level $\left(12 \mathrm{MPa}-\mathrm{m}^{1 / 2}\right)$. With this in mind, two different tests were performed at slightly lower $\Delta \mathrm{K}$ levels to repeat this observed behavior. It was postulated in the previous study that oxidation formed due to the high temperature may have played a role in the observed crack arrest. In the current study, the near threshold tests were performed at room temperature. 


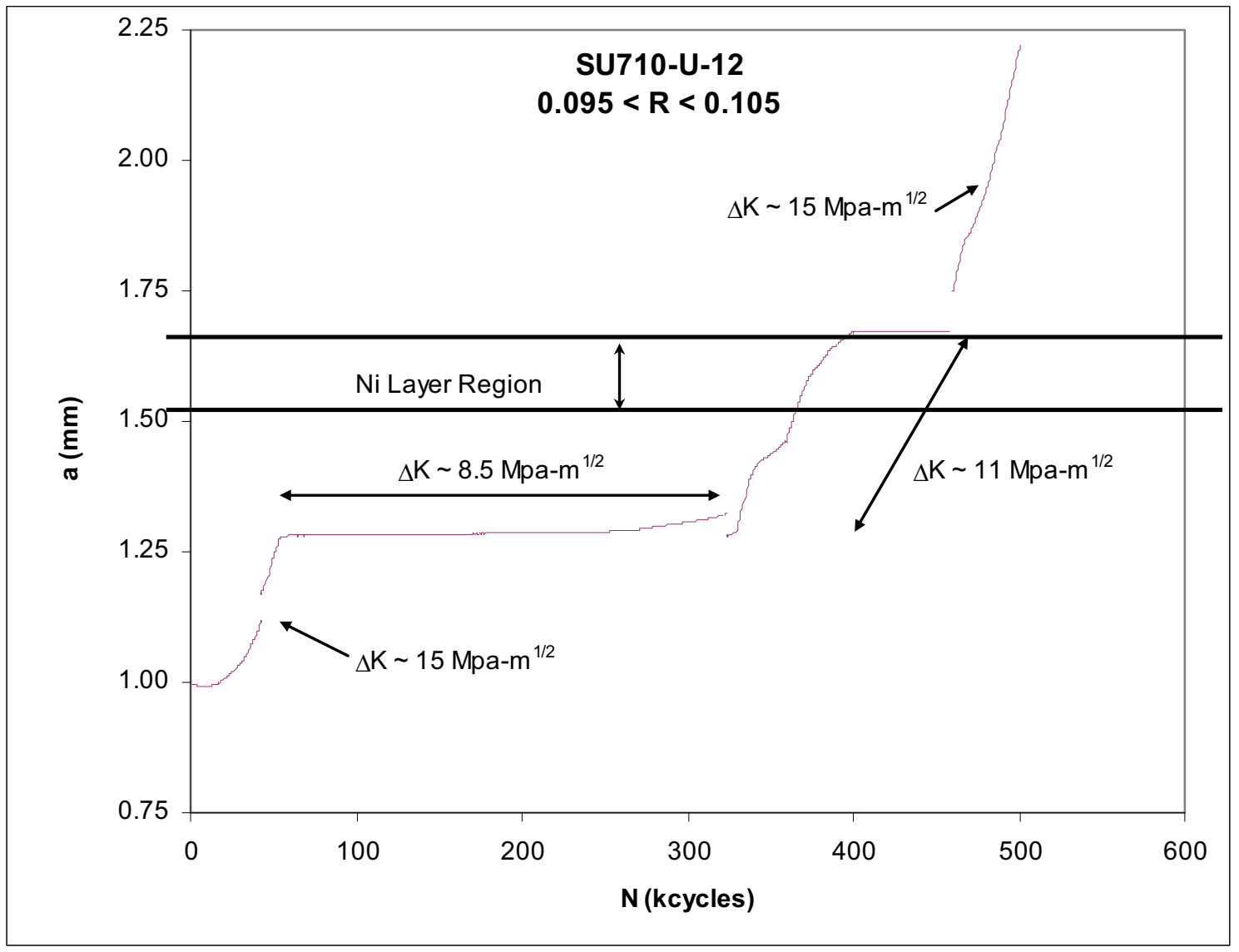

Figure 4: Near threshold crack arrest after nickel interlayer and ensuing crack growth with increased $\Delta K$. 


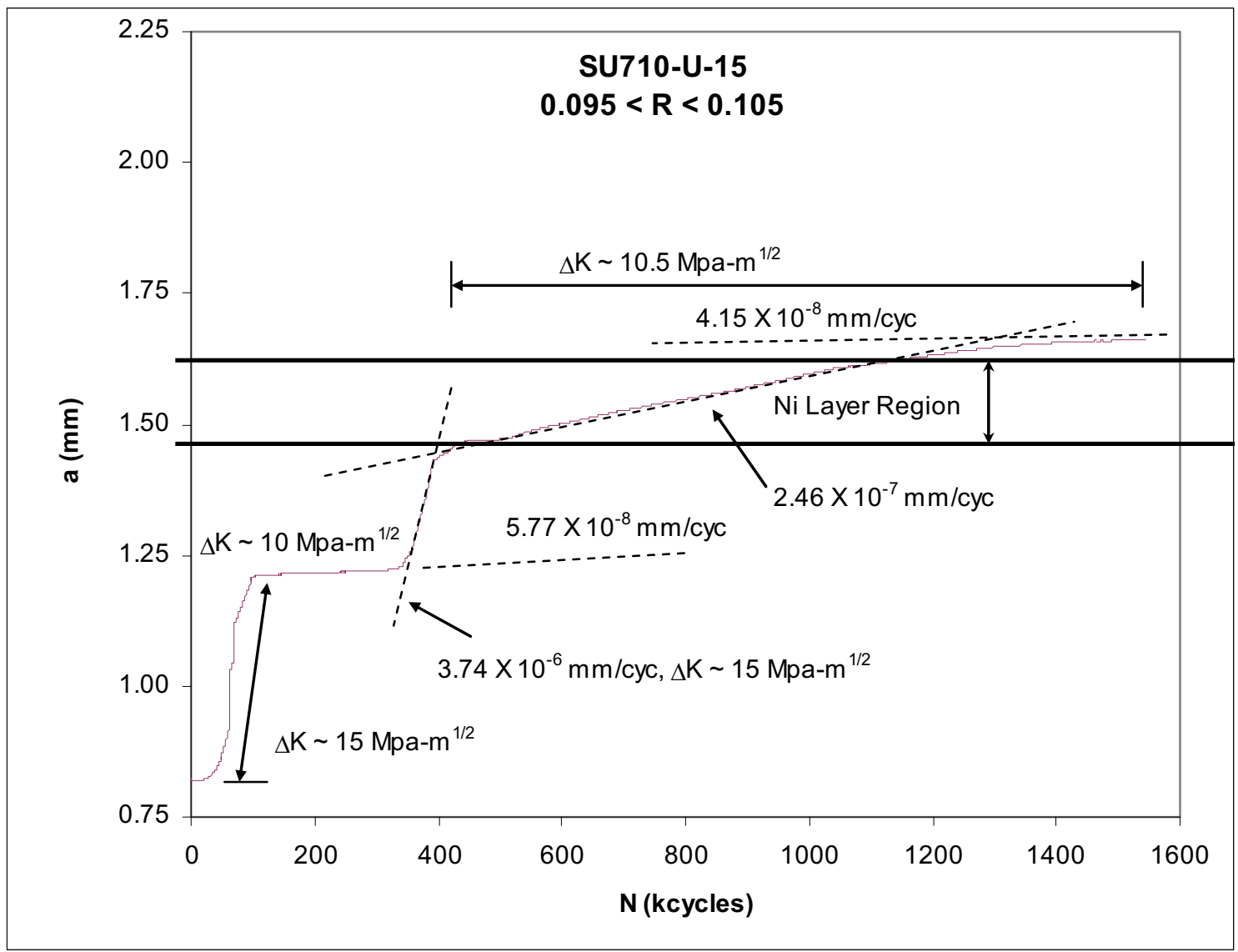

Figure 5: Practical crack arrest after nickel interlayer at near threshold $\Delta \mathrm{K}=10.5 \mathrm{MPa}-\mathrm{m}^{1 / 2}$.

As seen in Figures 4 and 5, fatigue cracks were arrested when the $\Delta \mathrm{K}$ level was held to near-threshold values $\left(\Delta \mathrm{K}_{\mathrm{th}} \sim=10 \mathrm{MPa}-\mathrm{m}^{1 / 2}[3]\right)$. Specimen SU710-U-12 (Figure 4) exhibited full arrest after passing through the nickel interlayer at $\Delta \mathrm{K}=11$ $\mathrm{MPa}-\mathrm{m}^{1 / 2}$, followed by re-initiation and growth when a larger, $\Delta \mathrm{K}=15 \mathrm{MPa}-\mathrm{m}^{1 / 2}$ was applied. Specimen SU710-U-15 (Figure 5) exhibited practical arrest after passing through the nickel interlayer at $\Delta \mathrm{K}=10.5 \mathrm{MPa}-\mathrm{m}^{1 / 2}$, with the crack growth rate slowing to an almost negligible $4.15 \times 10^{-8} \mathrm{~mm} /$ cycle. At this point the test was stopped so that the crack tip could be studied.

Following fatigue testing, specimen SU710-U-15 was polished on the surface and optical microscopy was used to observe the crack tip. Following the surface inspection, the specimen was ground to depths of $1 / 8,1 / 4,3 / 8$, and $1 / 2$ of the through thickness and re-polished and photographed at each step. This is discussed in section 3.5.

\subsection{Fracture testing}

Two specimens were fatigue pre-cracked to a point just prior to the nickel interlayer and then monotonically loaded in a fashion reflective of a standard $\mathrm{J}$ integral test. The failure loads were approximately $0.43 \mathrm{KN}$, corresponding to an 
approximate fracture toughness, $\mathrm{K}_{\mathrm{Q}} \sim=28 \mathrm{MPa}-\mathrm{m}^{1 / 2}$. A J-integral approximation is inappropriate because the crack immediately branched. Both specimens exhibited an altered crack path upon encountering the nickel interlayer, with the first (SU710-L-6) exhibiting a marked delamination at both the inner and outer borders of the interlayer, and the second (SU710-L-8) exhibiting an interesting pattern of several vertical cracks appearing in the interlayer. Figure 6 is a $100 \mathrm{X}$ optical micrograph of the crack tip region for specimen SU710-L-6, showing the clear delamination that was observed. Figure 7 is a $100 \mathrm{X}$ optical micrograph of the post-test crack tip region for specimen SU710-L-8, showing a formation of cracks within the nickel interlayer and a bifurcation of the main crack to join these smaller cracks. Figures 8 and 9 are 500X optical micrographs of the crack tip regions of specimens SU710-L-6 and SU710-L-8, respectively, showing the observed phenomenon more clearly. The 500X photo of SU710-L-6 is of the right hand wing of the crack.

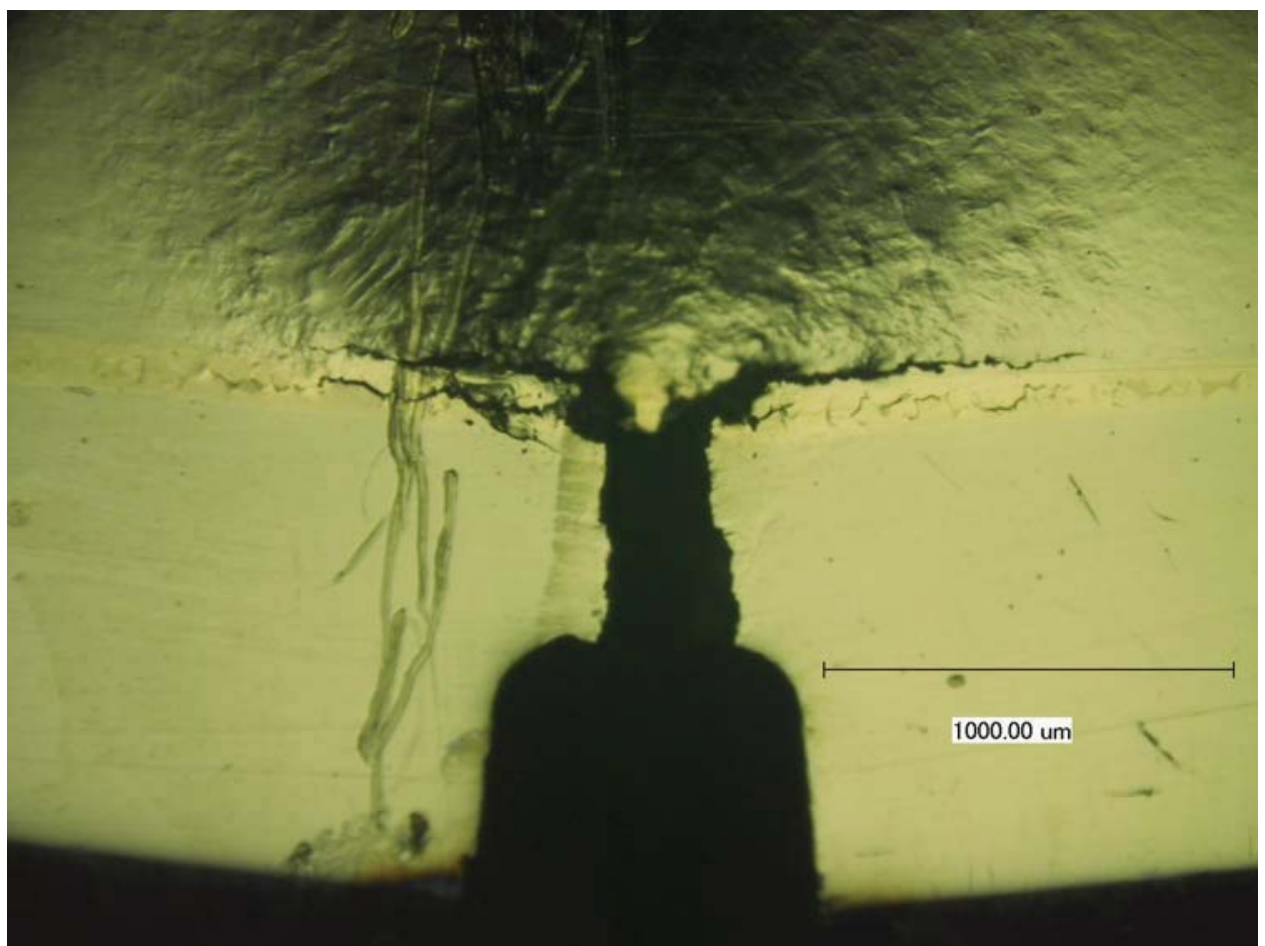

Figure 6: 100X micrograph of specimen SU710-L-6 showing delamination of the nickel interlayer following monotonic loading to $\mathrm{K} \sim=28 \mathrm{MPa}-\mathrm{m}^{1 / 2}$. 


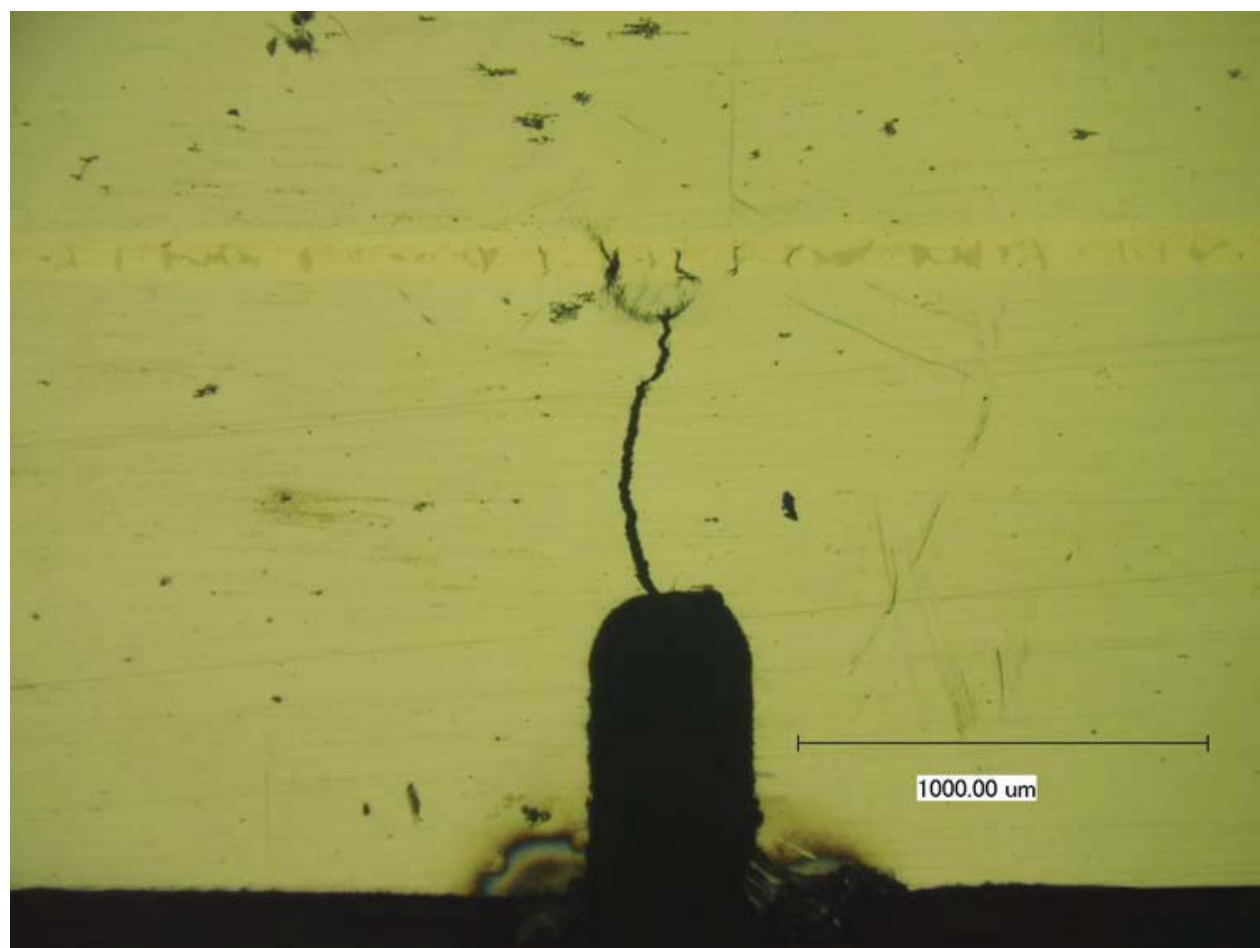

Figure 7: 100X micrograph of specimen SU710-L-8, showing vertical cracks appearing in the nickel interlayer following monotonic loading to $\mathrm{K}=28 \mathrm{MPa}-\mathrm{m}^{1 / 2}$.

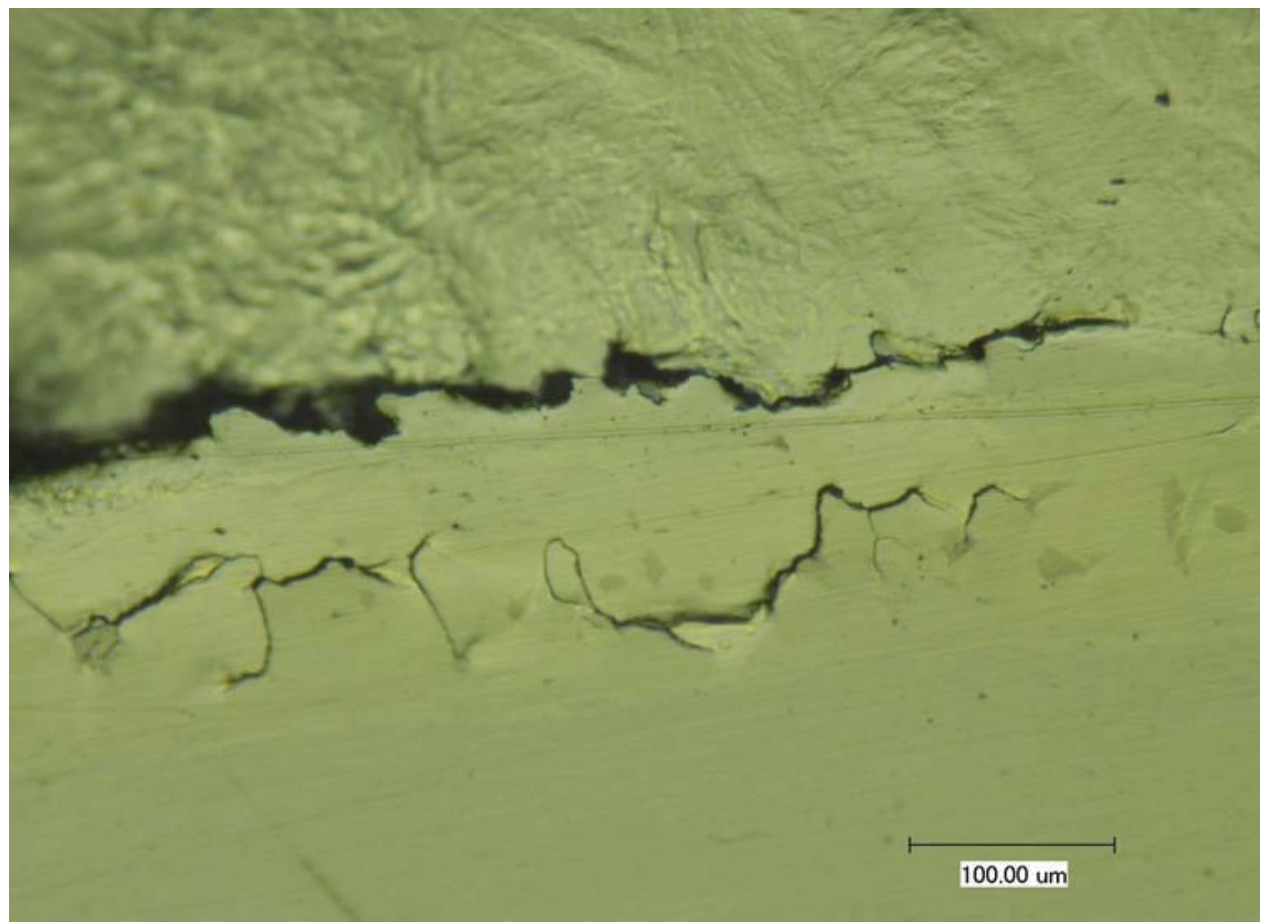

Figure 8: 500X optical micrograph of the right "wing" of the crack in specimen SU710-L-6 following monotonic loading. 


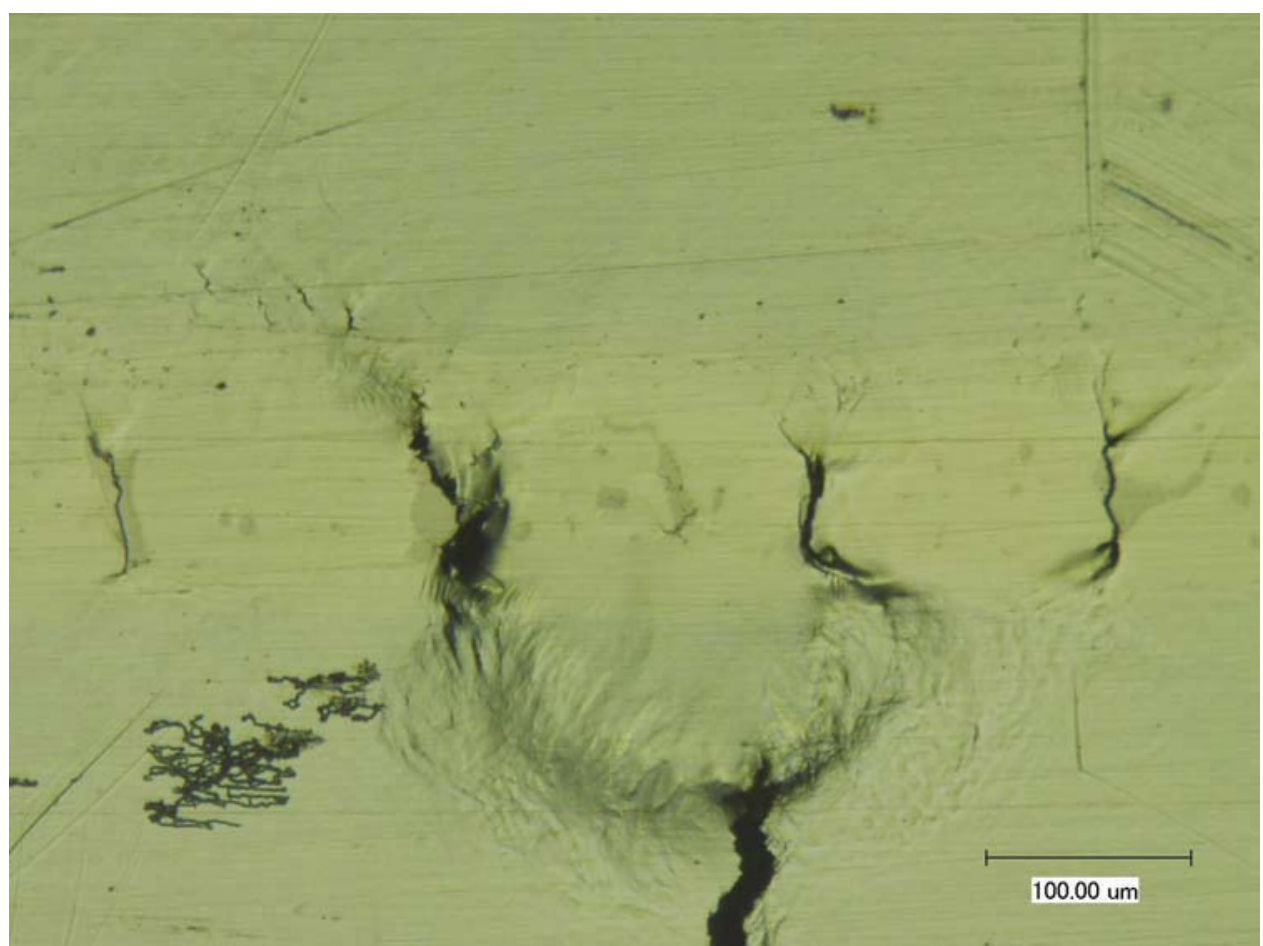

Figure 9: 500X optical micrograph of specimen SU710-L-8, showing appearance of vertical cracks following monotonic loading.

\subsection{Fractography/Microscopy}

Following fatigue testing, specimen SU710-U-9 was broken open using liquid nitrogen and the fracture surfaces were photographed using a Scanning Electron Microscope (SEM). The fracture surface does not exhibit a marked increase in fracture surface roughness on the far side of the nickel interlayer where the fatigue crack exhibited a temporary retardation of crack growth rate as was noted in [3]. The fracture appears to retain similar morphology on both sides of the nickel interlayer with a very slight increase in roughness. Figure 10 is a SEM overview of the fracture surface showing a 25X overview and a 100X closeup of the fracture morphology surrounding the nickel interlayer. Here, the crack grows from bottom to top. 

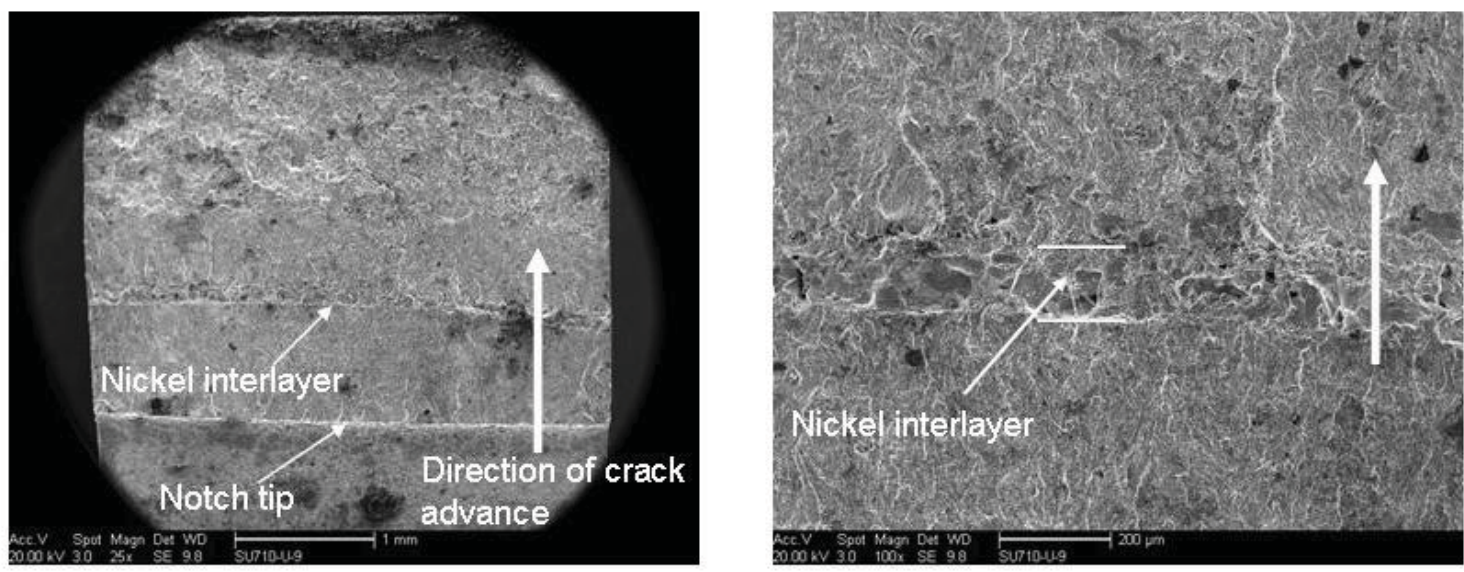

Figure 10: SEM overview of fracture surface on specimen SU710-U-9 showing fracture morphology following nickel interlayer.

The tortuous nature of the crack growth path in the nickel interlayer due to voids is also noted in this study. Figure 11 shows a SEM close-up of the nickel interlayer on the fracture surface of specimen SU710-U-9 (on the left) and SU710-U-12 (on the right). The voids are more evident in the SEM photograph of the nickel interlayer of specimen SU710-U-12, which was run at a nearthreshold $\Delta \mathrm{K}$ and exhibited full arrest. Additionally, the small, regular voids along the edge of the interlayer, noted and attributed to a Kirkendall effect in [1] and [4] are seen in Figure 12, an optical micrograph of the surface of specimen SU710U-9. Figure 12 also shows the typical, large voids present within the nickel interlayer.
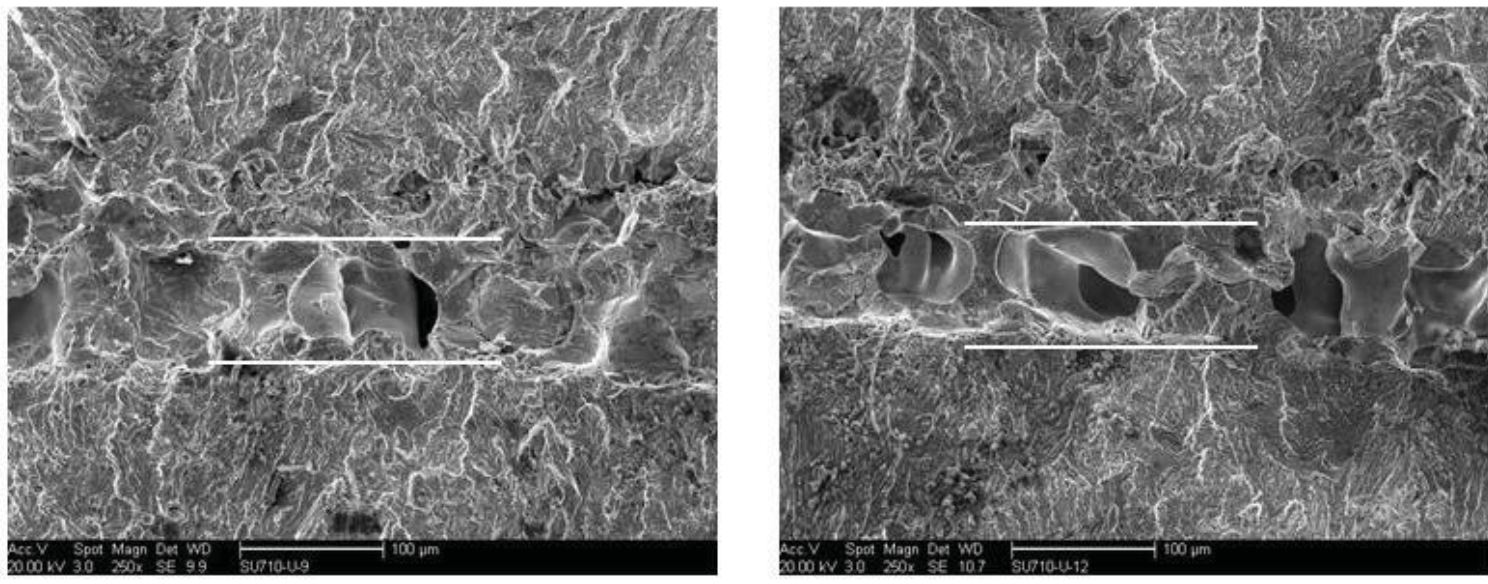

Figure 11: Comparison of morphology in nickel interlayer for steady state $\Delta \mathrm{K}$ crack growth (left) and near threshold $\Delta K$ crack growth (right). 


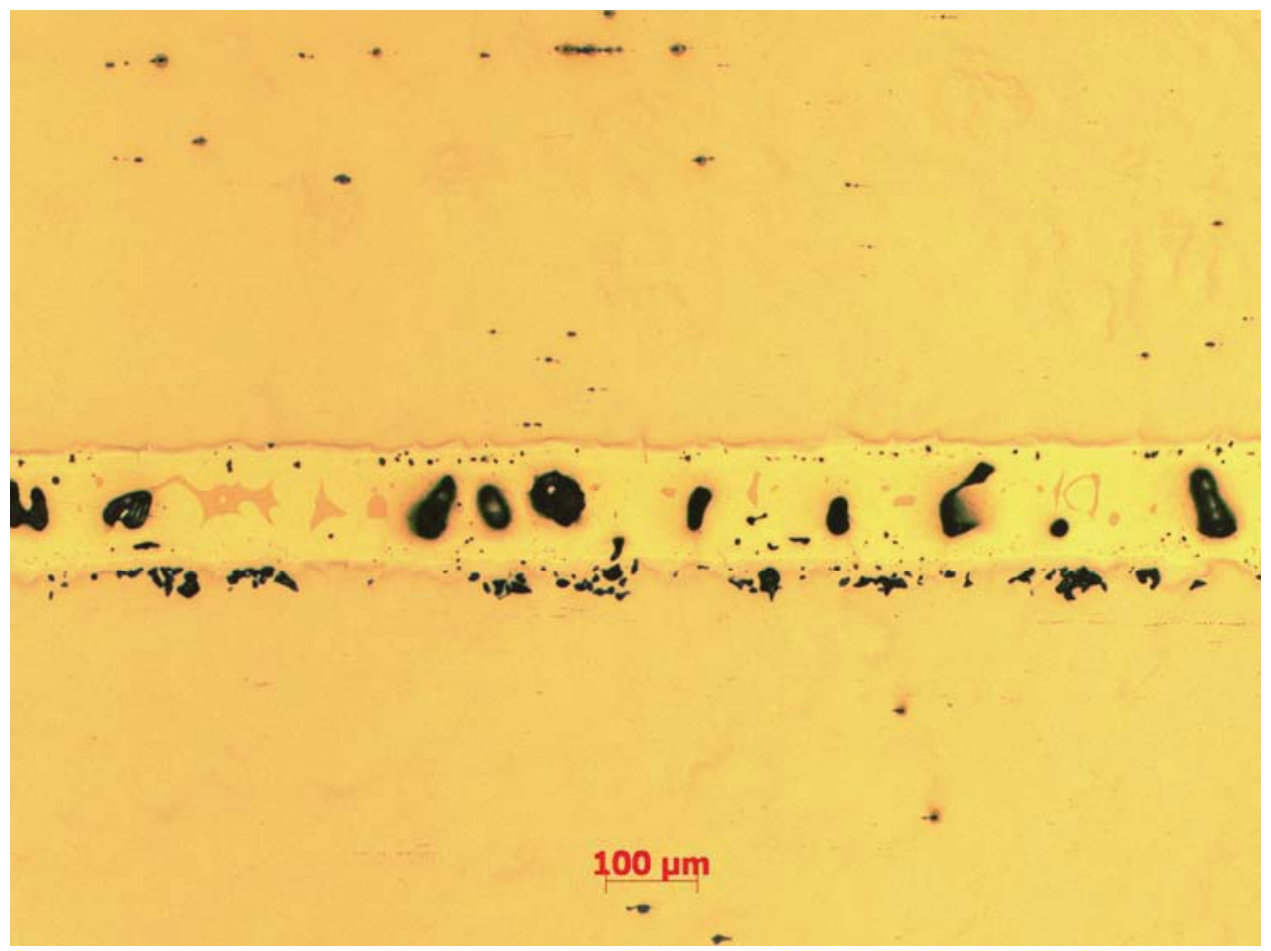

Figure 12: 50X Optical micrograph of specimen SU710-U-9 showing voids in nickel interlayer.

As mentioned previously, following testing to arrest, specimen SU710-U-15 was polished in several stages, and photographed to observe the nature of the crack tip through the thickness of the specimen since crack tip oxidation was noted as a possible cause of crack arrest in a single case in [3]. The optical micrographs show a clear appearance of a void at the crack tip in all of the micrographs. Thus the crack arrest is likely due to the presence of this void, however, no oxidation is noted here. Figure 13 is a $100 \mathrm{X}$ micrograph of the surface of specimen SU710$\mathrm{U}-15$, showing the crack path. Figure 14 is a compilation of images showing the crack tip at 500X magnification at the surface, 1/8 thickness, 1/4 thickness, 3/8 thickness, and $1 / 2$ thickness planes. In each micrograph, the crack path appears to preferentially orient itself toward voids, and appears to end in a void at each thickness plane. 


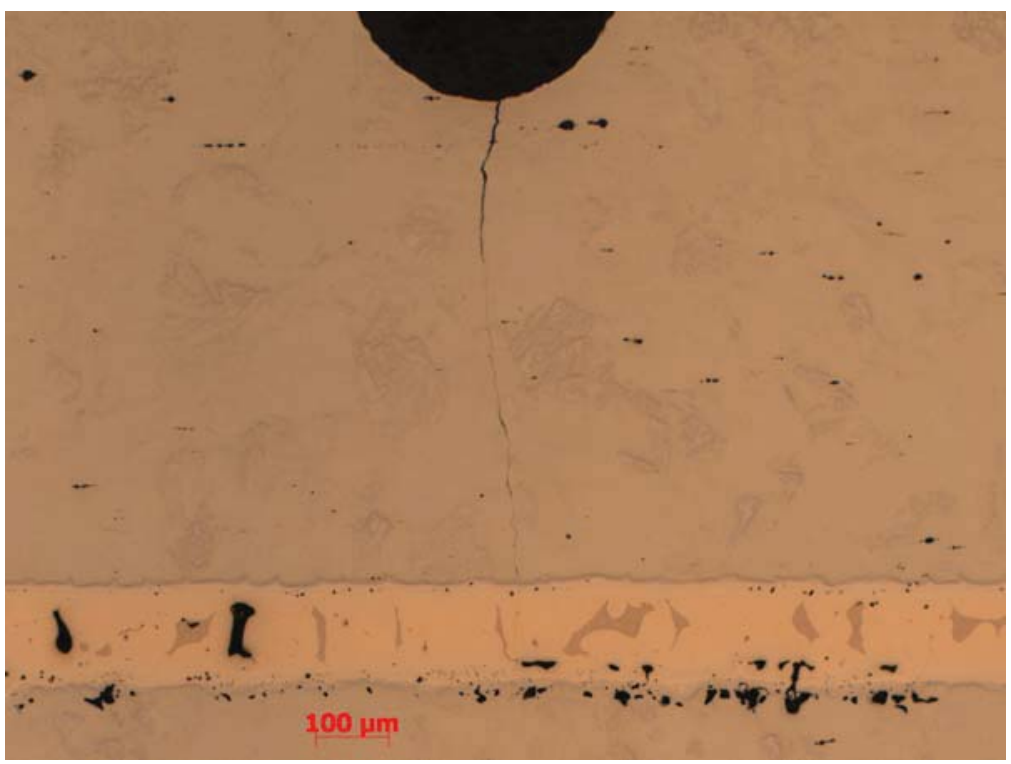

Figure 13: 100X Optical micrograph of the surface of specimen SU710-U-15 showing crack path and arrest on far edge of nickel interlayer (growth direction is top to bottom).

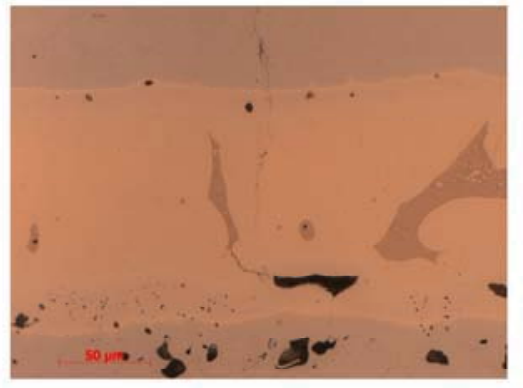

surface

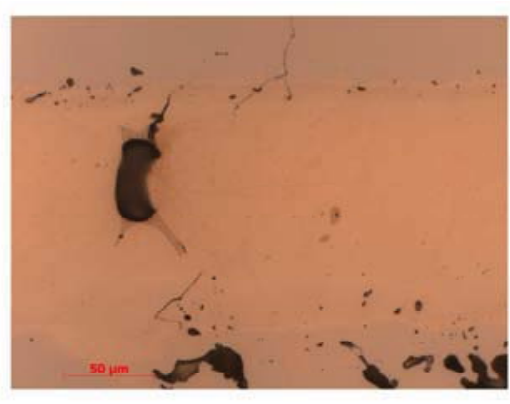

$1 / 4$ Thicknoss

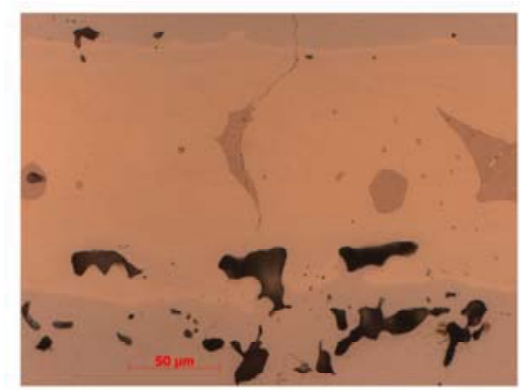

$1 / 8$ Thickness

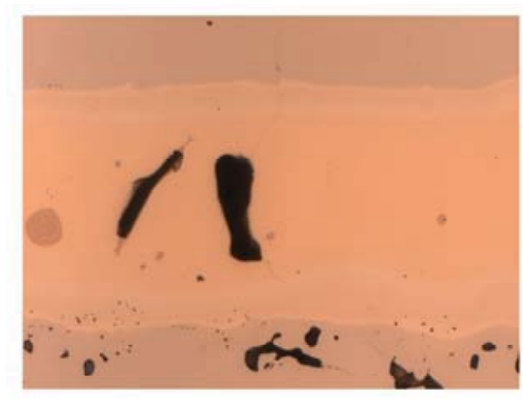

3/8 Thicknoss

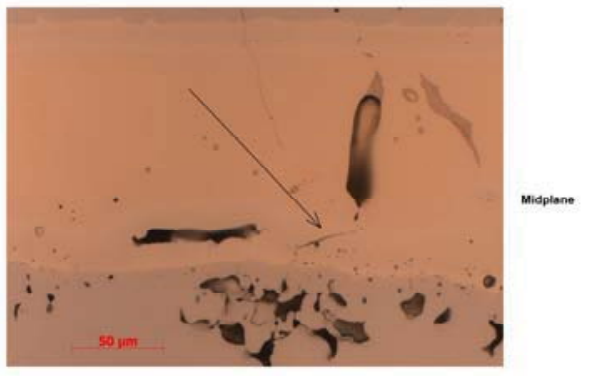

Figure 14: 500X montage of crack tips for several through-thickness planes in specimen SU710-U-15. 


\subsection{Micro-hardness testing}

Table 1 shows the hardness measurements taken in both the base material and nickel interlayer. It is noted that there was no hardening of the 2-1/4 $\mathrm{Cr} 1 \mathrm{Mo}$ (ASME SA213 T22) base material in service; the average values of $191 \mathrm{Hv}$ and $189 \mathrm{Hv}$ for SU710 U-9 and U-12, respectively are reasonable compared to the required sub-200 Hv required for ASME SA213 Gr T22 steel [6]. The average post service hardness values of $196 \mathrm{Hv} 100$, and $219 \mathrm{Hv} 100$ for the nickel interlayer in the two specimens are surprisingly low compared to the expected values. There were sporadic measurements in the $700 \mathrm{Hv} 100$ range, but these were assumed to have been spurious results as some of the micro-indentations fell on the previously observed [1] $\mathrm{Ni}_{-} \mathrm{Ni}_{3} \mathrm{P}$ eutectic inclusions. Figure 15 shows two microhardness indentations in a 1000X optical micrograph, one in the base nickel and one falling on a $\mathrm{Ni}_{-} \mathrm{Ni}_{3} \mathrm{P}$ inclusion.

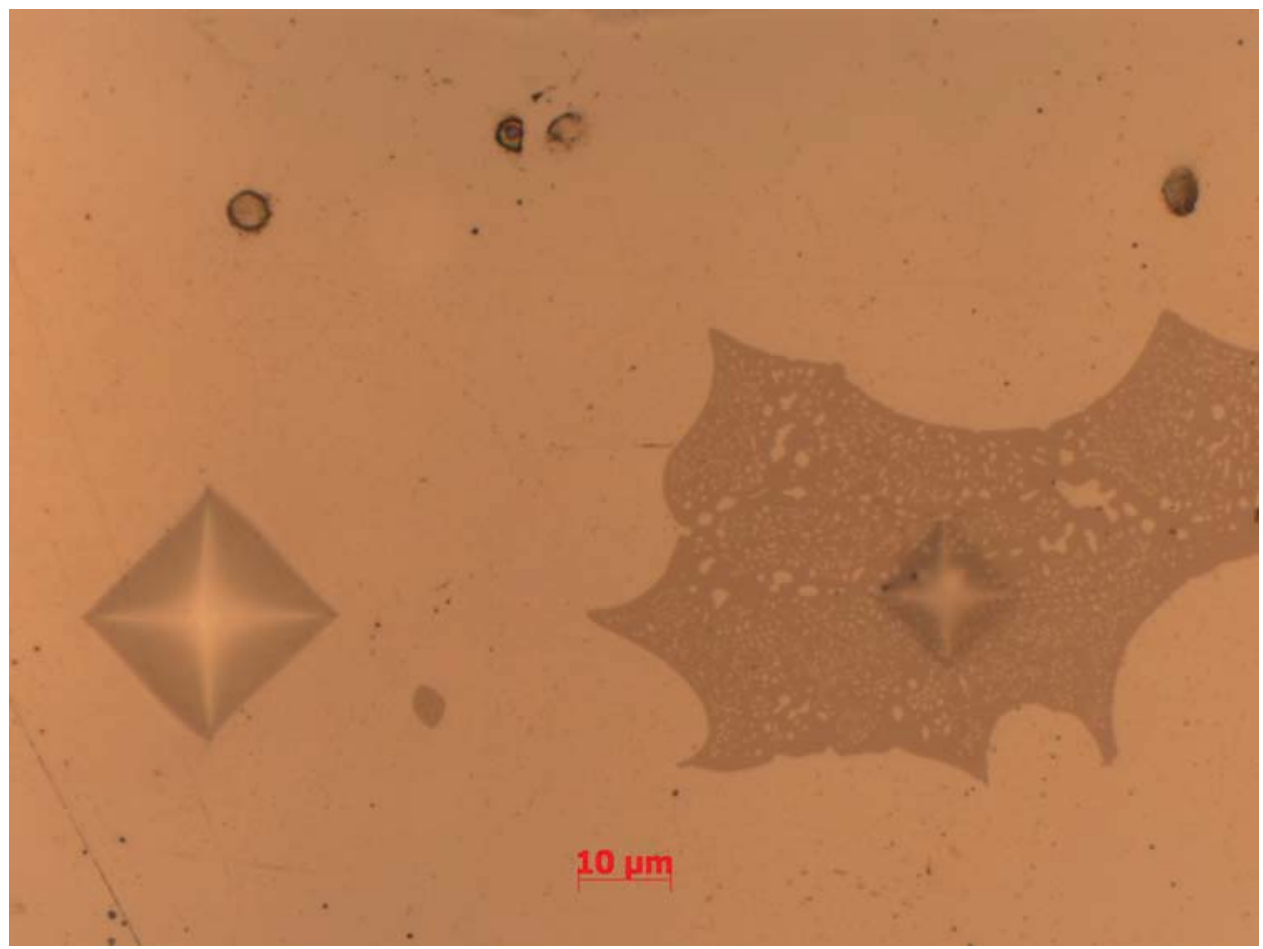

Figure 15: 1000X optical micrograph showing the relative size of hardness indentations in base nickel and $\mathrm{Ni}-\mathrm{Ni}_{3} \mathrm{P}$ eutectic inclusion. 


\begin{tabular}{|l|c|c|c|c|c|}
\hline SAMPLE ID. & $\begin{array}{c}\text { SU710- } \\
\text { U-9 } \\
\text { BASE } \\
\text { METAL }\end{array}$ & $\begin{array}{c}\text { SU710- } \\
\text { U-9 } \\
\text { NICKEL }\end{array}$ & $\begin{array}{c}\text { SU710- } \\
\text { U-12 } \\
\text { BASE } \\
\text { METAL }\end{array}$ & $\begin{array}{c}\text { SU710- } \\
\text { U-12 } \\
\text { NICKEL }\end{array}$ & \\
\hline HV100 Indentation \#1 & 186 & 192 & 192 & 225 & \\
\hline HV100 Indentation \#2 & 192 & 204 & 184 & 227 & \\
\hline HV100 Indentation \#3 & 192 & 212 & 192 & 221 & \\
\hline HV100 Indentation \#4 & 196 & 201 & 191 & 226 & \\
\hline HV100 Indentation \#5 & 193 & 218 & 189 & 217 & \\
\hline HV100 Indentation \#6 & & 181 & & 201 & \\
\hline HV100 Indentation \#7 & & 177 & & 206 & \\
\hline HV100 Indentation \#8 & & 172 & & 233 & \\
\hline HV100 Indentation \#9 & & 207 & & 236 & \\
\hline HV100 Indentation \#10 & & 208 & & 207 & \\
\hline HV100 Average & 191 & 196 & 189 & 219 & \\
\hline
\end{tabular}

Table 1: Microhardness (Hv100) for 2-1/4 Cr-1Mo and nickel interlayer for two specimens.

\section{Discussion}

There were no fatigue results contradicting what had been previously reported in [1] and [3]. Again, no arrest was observed at $\Delta \mathrm{K}$ above $12 \mathrm{Mpa}-\mathrm{m}^{1 / 2}$. The specimens that did exhibit arrest were tested at $\Delta \mathrm{K}$ levels just slightly above the threshold $\Delta \mathrm{K}$ value of $10 \mathrm{MPa}-\mathrm{m}^{1 / 2}$, which was slightly more promising than the results reported in [1] and [3], but it appears that these crack arrests were the result of a combination of low $\Delta \mathrm{K}$ and the presence of voids within and near the edges of the nickel interlayer.

The monotonic load fracture tests verify the Charpy test results reported in [4]. Upon reaching the nickel interlayer, the crack path is altered and either branches into several smaller cracks, or becomes a delamination of the nickel interlayer from the base material.

When compared to published results, hardness values in the nickel interlayer were considerably lower. For Ni-P alloys with nominally 7-9 \% P, hardness values are reported to be between 500 and $600 \mathrm{~kg} / \mathrm{mm}^{2}$ in [2]. A 7-9\%P braze should produce a near $50 \%-50 \% \%$ mixture of nickel and $\mathrm{Ni}_{3} \mathrm{P}$, although the eutectic reaction produces $73 \%$ of $\mathrm{Ni}_{3} \mathrm{P}$. Therefore one would expect to see areas of eutectic mixture and areas of relatively pure nickel. The hardness values cited above would necessarily be created by a rather fine dispersion of nickel-nickel phosphide $\left(\mathrm{Ni}_{-} \mathrm{Ni}_{3} \mathrm{P}\right)$ eutectic in nickel. The microstructures shown in these layers indicate that the phosphide-containing areas have coarsened, 
leaving large areas of relatively pure nickel. This would have a lower hardness than that expected in a dispersion created upon cooling from the brazing temperature.

The currently measured values were 196-219 Hv100 and therefore imply a softening during service. These values ( 200 Vickers Hardness) are more typical of commercial pure nickel with a moderate (40-50\%) amount of coldwork [5], suggesting that the phosphide originally present in the nickel braze may have precipitated almost entirely to the previously observed $\mathrm{Ni}_{-} \mathrm{Ni}_{3} \mathrm{P}$ eutectic inclusions. The occasional hardness value measured in the current study of $\sim 700 \mathrm{Hv} 100$ would lend credence to this possibility as these high values were obtained when a hardness indentation fell on an inclusion. Original hardness data for the nickel interlayer is unavailable.

\section{Conclusions}

Fatigue behavior observed in the current study was similar to that reported in [1] and [3]. Within the Paris Law regime $\left(\Delta \mathrm{K}=15 \mathrm{MPa}-\mathrm{m}^{1 / 2}\right)$, the crack growth rate exhibited the previously noted steady state rate up to the nickel interlayer, followed by an acceleration through the nickel interlayer, and a short retardation of growth rate following the nickel interlayer. At $\Delta \mathrm{K}$ levels slightly above the previously reported threshold $\Delta \mathrm{K}=10 \mathrm{MPa}-\mathrm{m}^{1 / 2}$ [3], the fatigue crack was shown to arrest following passage through the nickel interlayer. This was attributable in at least one case to encountering a void within the nickel interlayer.

There is no evidence suggesting a hardening of the nickel interlayer in service. In fact, as pointed out in the discussion, the nickel interlayer actually likely became softened during service as the phosphide precipitated into $\mathrm{Ni}^{-} \mathrm{Ni}_{3} \mathrm{P}$ eutectic inclusions. Unfortunately, there is no data on the original hardness of the Ni interlayer for comparison, but the fact that the general hardness of the $\mathrm{Ni}$ interlayer is closer to that of relatively pure nickel supports this conclusion.

The nickel interlayer does not appear to be a reliable mitigation for fatigue crack propagation. The only instances where "arrest" occurs are for near threshold $\Delta \mathrm{K}$ regimes of loading, or for single monotonic overloads. The nature of the nickel interlayer (e.g. voids, $\mathrm{Ni}_{-} \mathrm{Ni}_{3} \mathrm{P}$ inclusions) appears to be a contributor to an acceleration of cracks within the interlayer, rather than a crack growth inhibitor. 


\section{References}

1. Totemeier, T. C., Wachs, D. M, Porter, D. L and Kisohara, N.. "Fatigue Testing of Metallurgically-Bonded EBR-II Superheater Tubes," Journal of Nuclear Materials, v. 376 (2008) pp 38-46..

2. Safrenek, W. H., The Properties of Electrodeposited Metals and Alloys, A Handbook, Second Edition, American Electroplaters and Surface Finishers Society, 1986, page 510.

3. Totemeier, T. C., "Fatigue Testing of Metallurgically-Bonded EBR-II Superheater Tubes," Idaho National Laboratory Report INL/EXT-06$12011,2006$.

4. Wachs, D. M., Keiser, D. D., Porter, D. L., and Kisohara, N., "EBR-II Superheater Duplex Tube Examination," Nuclear Technology, Vol. 164, 2008, pp 465-473.

5. Everhart, J. L., Engineering Properties of Nickel and Nickel Alloys, Plenum Press, 1971.

6. ASME standard SA-213, American Society of Mechanical Engineers. 